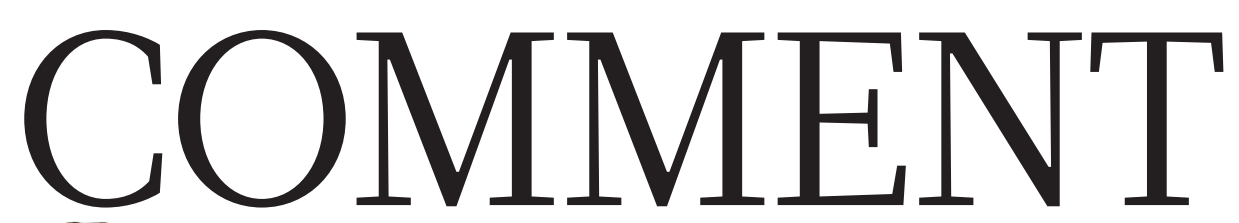

LIGHT Reflections on a THEATRE Tom Stoppard tackles thousand-year-old of the science of consciousness, optics text $\mathbf{p} .164$ using fraud and finance p.166
CONSERVATION Fishing lobbyists re-open debate over Brazil's Red List $\mathbf{p} \mathbf{1 6 7}$
OBITUARY Hubert Markl, architect of German science system, remembered $\mathbf{p} . \mathbf{1 6 8}$

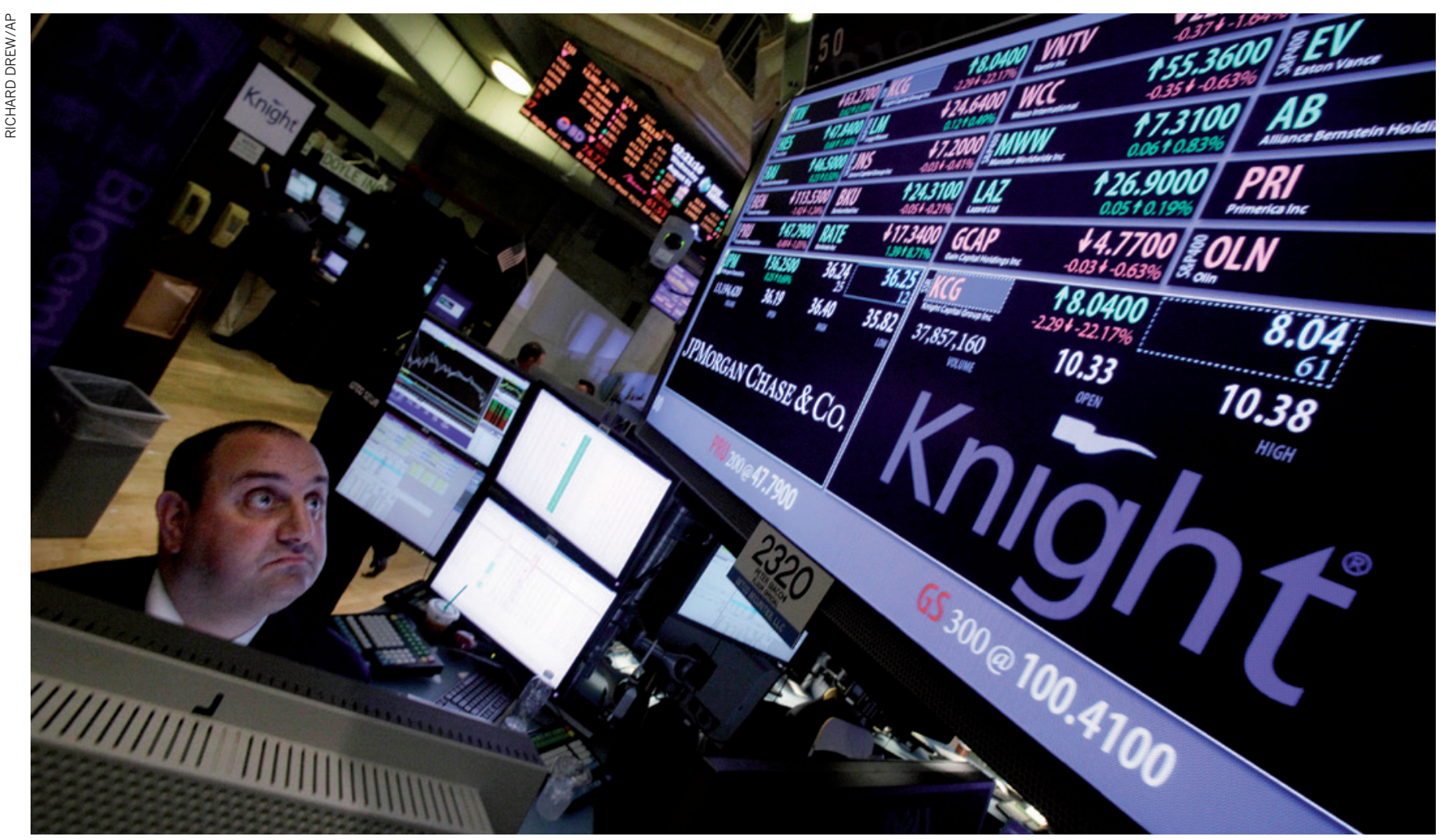

A software glitch at trading firm Knight Capital caused losses of US\$440 million in a single day in 2012.

\title{
Trading at the speed of light
}

To minimize risks, we must learn more about how financial markets operate at ever faster rates, urges Mark Buchanan.

$\mathrm{F}$

inancial traders are in a race to make transactions ever faster. In today's hightech exchanges, firms can execute more than 100,000 trades in a second for a single customer. This summer, London and New York's financial centres will become able to communicate 2.6 milliseconds (about 10\%) faster after the opening of a transatlantic fibre-optic line dubbed the Hibernia Express, costing US $\$ 300$ million. As technology advances, trading speed is increasingly limited only by fundamental physics, and the ultimate barrier - the speed of light.

Through glass optical fibres, information travels at two-thirds of the speed of light in a vacuum (300,000 kilometres per second). To go faster, data must travel through the air. The corridors between Chicago and New York and New Jersey, and between London and Frankfurt, are bristling with efficient microwave and millimetre-wave links. An even more efficient network of lasers based on military technology for in-flight signalling between aeroplanes — has been installed to link the New York and New

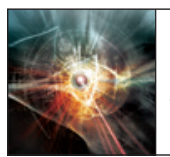

Jersey as well as the London and Frankfurt financial exchanges ${ }^{1}$.

Next up may be hollow-core fibre cables, through which light would travel in a tiny air gap at light speed. Trading firms speculate about a fleet of balloons or uncrewed solarpowered drones carrying signal repeaters to support a network of links across the oceans. In a decade or so, firms may even communicate using neutrinos, which travel at the speed of light and can go through obstacles, including Earth. It all spells big profits for high-tech trading firms, which now account for around $50 \%$ of equity trading in the United States and in Europe. 


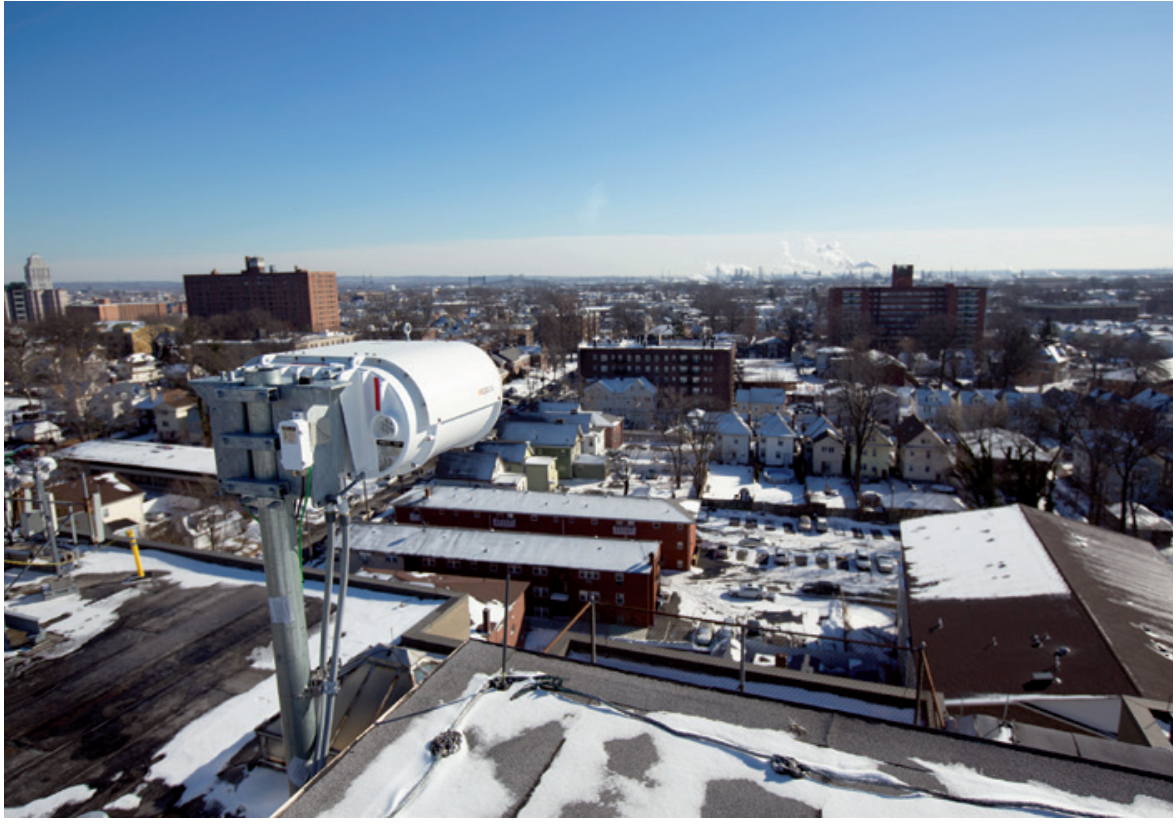

Laser units on rooftops connect New Jersey's Nasdaq data centre with the New York Stock Exchange.

But some firms claim that uneven access to extreme speed erodes trading fairness. And system-wide failures occur when algorithms interact in unforeseen ways - such as in the 'flash crash' of 6 May 2010, when the Dow Jones Industrial Average fell by the largest daily amount ever within minutes (see 'Flash crash'). No one knows when a similar event might spill over into global markets.

Avoiding these risks will require intensive research on how markets work - as complex ecologies of interacting algorithms - and how countermeasures could avert disasters.

\section{GETTING AHEAD}

High-frequency trading relies on fast computers, algorithms for deciding what and when to buy or sell, and live feeds of financial data from exchanges. Every microsecond of advantage counts. Faster data links between exchanges minimize the time it takes to make a trade; firms fight over whose computer can be placed closest; traders jockey to sit closer to the pipe. It all costs money - renting fast links costs around $\$ 10,000$ per month.

Communications technology is a limiting factor. Fibre-optic cables carry the most data, but do not give the speed required. The fastest links carry information over a geodesic arc - the shortest path on Earth's surface between two points. So line-of-sight microwaves are a better option; millimetre waves and lasers are better yet, because they have higher data densities.

Open-air communications systems are prone to weather disruption. Anova Technologies, a network provider for trading firms headquartered in Chicago, Illinois, has augmented its New York laser network with millimetre waves to overcome rain, fog and snow. Adaptive alignment mechanisms keep the links working even if winds make towers twist by up to $3^{\circ}$. But microwaves and lasers cannot be used over long distances without repeaters. They attenuate quickly in the atmosphere and do not curve around Earth.

Some economists question the worth of such investments. Joseph Stiglitz, a Nobel laureate in economics, is among those who argue that rapid trading is socially useless ${ }^{2}$. High-frequency firms quickly cancel about $95 \%$ of the orders they make ${ }^{3}$. Worse, speed may impede proper market function. The traditional purpose of financial markets is to pool diverse information from many people to channel investment resources. That requires trading based on insight, depth of study and patience - all foreign to the highfrequency algorithm-based system ${ }^{2}$.

\section{GOOD, BAD AND UGLY}

Fast trading has pros and cons. First, it gives markets 'liquidity' - it makes it easier for investors to find trading partners at reasonable prices. Liquid markets benefit trade in the same way that free-flowing traffic helps transport. Such markets tend to have low 'spreads' - the difference between the prices at which one can buy or sell a stock, which reflects the fee that dealers demand and thus transaction costs for investors. As high-frequency trading has grown over the past decade, spreads in many markets have fallen, making trading cheaper ${ }^{4}$.

Even so, the liquidity that computer trading creates is fleeting, and it can fail when markets get unruly. Wildly fluctuating prices mean bigger risks for traders who earn a living by 'market making' - standing ready to buy or sell stocks at any moment and earning a profit from the spread. The algorithms they use to trade profitably make more errors and are programmed to get out of the market altogether when markets get too volatile. The problem is exacerbated by the similarity of the algorithms used by many high-frequency trading firms - they all bail out at the same time. That is what happened in the 2010 flash crash. (Of course, this problem happens with human traders too, who flee markets when they get too scary.)

Another good thing about high-frequency trading is that it helps to synchronize prices across markets ${ }^{5}$. It takes time to digest information, draw out implications and align prices. If prices in sugar or high-fructose corn syrup rose, stocks in Coca Cola would fall quickly; those of less well-known softdrink companies would take longer. Highfrequency trade speeds up that process. In 2000 , it took minutes on average for a price change in one security to flow to others. Now it takes less than ten seconds. Not everyone likes this: fast synchronization wipes out profit opportunities for firms that make money by knowing about the momentary price imbalances.

\section{MARKET DYNAMICS}

Some high-frequency firms exploit an anachronism in the structure of markets. By US law, each regulated exchange must feed its best available prices for a stock, sale and purchase, to a central facility, which uses that information to establish a public National Best Bid and Offer (NBBO). But exchanges also sell faster proprietary data feeds that firms can use to predict the NBBO in advance, gaining an edge over anyone using the public information alone. Hence, high-frequency firms can move in ahead of slower traders. This tends to further synchronize prices. Big investors such as mutual funds and pension

\section{FLASH CRASH}

On 6 May 2010, the market value of the Dow Jones Industrial Average index fell by $9 \%$. but recovered in minutes. High-speed trading algorithms were in part to blame.

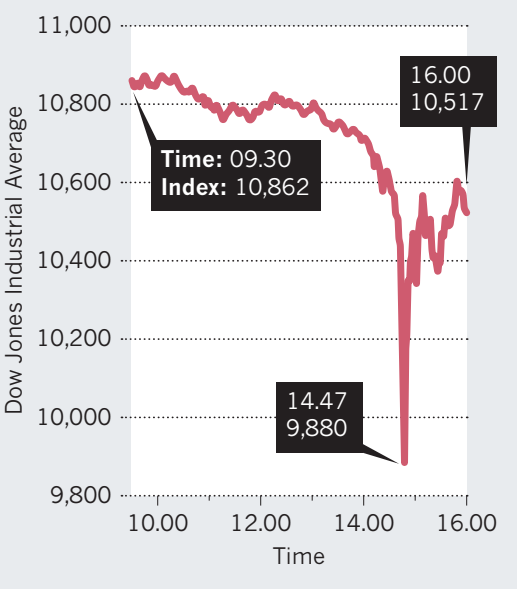


$\infty$ funds, which act on real-world insight and

压 information with a long-term view, are

㟧 among those which lose out, although they

also benefit from the lower spreads created by high-frequency traders.

In the United States, some large trading firms have set up private trading spaces to eliminate the timing edge for highfrequency traders. For example, the alternative trading system IEX, launched in 2013, aims to stop exploitation of the NBBO. It has introduced a trading 'speed bump' an automatic delay of 350 microseconds - which makes it impossible for traders to benefit from the faster feeds. IEX has already attracted about $1 \%$ of stock-trading volume in the United States. Firms in other countries may follow suit.

With computer codes carrying out trades with real-world consequences at a rate beyond that at which humans can intervene, the impacts of coding errors and digital glitches can spiral quickly. In 2012, a flaw in the algorithms of one of the largest US highfrequency trading firms, Knight Capital, caused losses of $\$ 440$ million in 45 minutes as its system bought at higher prices than it sold.

Sudden spikes or 'fractures' in the prices of stocks are increasingly common. Tens of thousands of times in the past few years, stock values have changed by $1 \%$ in less than 0.04 of a second ${ }^{6}$. The flash crash of 2010 happened at around 2.45 p.m. New York time, and markets recovered in about 15 minutes. Had it struck just before closing time in New York, the shock would have affected markets worldwide and recovery would have taken longer. Some investors speculate about a 'splash crash', in which a massive spike in one market disrupts or freezes trade in foreign exchange, futures, commodities, bonds and other assets, potentially triggering a global economic crisis.

Some researchers ${ }^{6}$ suggest that the spikes reflect a fundamental transformation of market dynamics, linked to the necessity for firms to use simple algorithms to maximize running speed.

\section{SYSTEMIC RISKS}

The nature of financial markets today is vastly different from that in the past. Rather than reflecting the collective decisions of people, they belie the behaviour of complex webs of technologies and their interactions with humans. The potential for global problems is increasing as high-frequency trading has moved into international markets for futures and other assets ${ }^{7}$. No industry including energy and food, insurance and banking - is immune from disruption.

In future, when airborne laser networks span the oceans, things may get even stranger. The location at which traders get the earliest possible information from two exchanges lies at their mid-point - between

\section{FAST TRADING HOTSPOTS}

The speed of light is the ultimate limit to how rapidly trades can be made between financial centres (•) - it would take signals travelling at this speed 67 milliseconds to travel halfway around the Earth The midpoints between exchanges $(\bullet)$ are the best places to site high-frequency trading computers because they access information from both simultaneously and with the minimum delay.

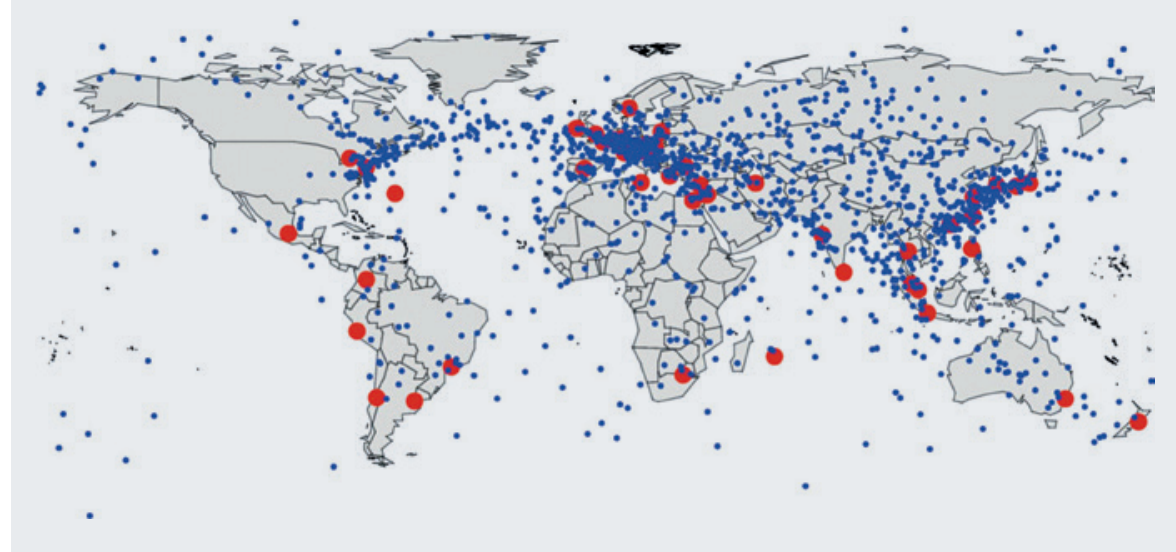

Chicago and London, this is in the middle of the Atlantic Ocean. At such a site, traders could exploit a technique called 'relativistic arbitrage ${ }^{88}$ to profit from momentary imbalances in prices in Chicago and London.

To explain: special relativity says that nothing can travel faster than the speed of light, $c$. Hence, a trader standing a distance $D$ away from an exchange can find out what happened there, in the best circumstance, at a time $T=D / c$ after it happened. Between major trading centres around the globe, such delays can be from a few to tens of milliseconds. If a trader stands halfway between the two exchanges, he or she will receive information from both after the same interval, $T=D / c$. Anywhere else, the distance to at least one of the exchanges would be greater and information would take longer to get there.

In other words, within a few years it may become profitable to station a ship or

"The impacts
of coding
errors and
digital
glitches
can spiral
quickly."
other trading platform near halfway points between pairs of financial centres worldwide (see 'Fasttrading hotspots'). That said, the profits earned by highfrequency firms have fallen in recent years, suggesting that most of the easy opportunities for money-making have already been taken.

If in ten years the wheels of the global financial system really will be greased by firms signalling from New York to Melbourne at Einstein's speed limit, research and policy-making should focus on two questions. First, how to avoid the biggest things that can go wrong; and second, how to make markets work as well as they can to serve society.

The first challenge requires more research into the dynamics of markets that are run by algorithms rather than investors. Computer scientists, mathematicians and economists need to work together to understand what drives flash crashes and how changes in market structures might avoid them. What 'circuit breakers', so to speak, might keep events from running out of control?

Second, researchers and policy-makers need to assess how to regulate markets to make them serve the purpose of boosting real economic investment. Algorithmic trading has been given wide latitude for the past two decades, under the assumption that firms making a profit must be helping the market. Finance research ${ }^{9}$ suggests that there may be an optimal speed for trading that today's markets have already far surpassed.

Mark Buchanan is a science writer based in the United Kingdom. His latest book is Forecast: What Physics, Meteorology and the Natural Sciences Can Teach Us About Economics.

e-mail:buchanan.mark@gmail.com

1. Patterson, S. 'High-Speed Stock Traders Turn to Laser Beams' The Wall Street Journal (12 February 2014).

2. Stiglitz, J. E. 'Tapping the Brakes: Are Less Active Markets Safer and Better for the Economy?' Paper given at 2014 Financial Markets Conference (2014); available at http://go.nature. com/ushstd.

3. Salmon, F. 'The problem with high frequency trading' Reuters (2012); available at http:// go.nature.com/ejnucs.

4. Hendershott, T., Jones, C. M. \& Menkveld, A. J. J. Finance 66, 1-33 (2011).

5. Gerig, A. Preprint at http://arxiv.org/ abs/1211.1919 (2012).

6. Johnson, N. et al. Preprint at http://arxiv.org/ abs/1202.1448 (2012)

7. Cliff, D. \& Northrop, L. The Global Financial Markets: An Ultra-Large-Scale Systems Perspective (UK Government Office for Science, 2010).

8. Wissner-Gross, A. D. \& Freer, C. E. Phys. Rev. E 82, 056104 (2010)

9. Fricke, D. \& Gerig, A. Preprint available at http:// dx.doi.org/10.2139/ssrn.2363114 (2015) 